Psychother Psychosom 2018;87:308-310

DOI: $10.1159 / 000491933$

\section{The Impact of Depressive Disorder Symptoms and Subtypes on 6-Year Incidence of Somatic Diseases}

\author{
Roxanne Gaspersz ${ }^{\mathrm{a}}$ Femke Lamers $^{\mathrm{a}}$ Aartjan T.F. Beekman ${ }^{\mathrm{a}}$ \\ Albert M. van Hemert ${ }^{\text {b }}$ Robert A. Schoevers ${ }^{c}$ \\ Brenda W.J.H. Penninx ${ }^{a-c}$ \\ ${ }^{a}$ Department of Psychiatry, Amsterdam Public Health Research \\ Institute, VU University Medical Center, Amsterdam, The

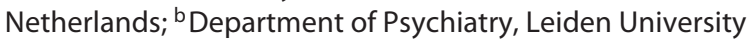 \\ Medical Center, Leiden, The Netherlands; ${ }^{\circ}$ Department of \\ Psychiatry, University Medical Center Groningen, University of \\ Groningen, Groningen, The Netherlands
}

\section{Dear Editor,}

Major depressive disorder (MDD) is associated with excess onset of a multitude of somatic diseases, for instance cardiovascular diseases, diabetes and to a lesser extent cancer [1-3]. Since MDD plus somatic disease comorbidity increases the negative impact on public health, gaining insight into which depression characteristics contribute to the onset of somatic diseases is necessary. This may improve prevention strategies by targeting prevention to those with specific depression characteristics and pinpoint more specific innovative treatment targets, from which both depressed patients as well as society may greatly benefit. However, not many studies have examined the impact of different clinical depression characteristics on incidence risks of somatic diseases. Distinct depressive subtypes may differ in underlying pathophysiology and subsequently may have a differential risk of somatic diseases [4]. This study examines whether the 6-year incidence of common somatic diseases differs between current and remitted MDD persons with healthy controls. Furthermore, the impact of MDD on somatic disease incidence was examined by exploring the role of clinical depression characteristics (severity, symptom clusters, individual symptoms and subtypes).

Baseline, 2-, 4- and 6-year follow-up data were used from the Netherlands Study of Depression and Anxiety, a longitudinal cohort study including 2,981 participants (aged 18-65 years) [5] (more details in the suppl. material; for all suppl. material, see www.karger.com/doi/10.1159/000491933). Eligible participants who had available data on at least 1 follow-up assessment (2-, 4-, 6-year follow-up) were 968 current (6-month recency) MDD patients, 482 remitted (presence of lifetime MDD but without an MDD or anxiety disorder in the past 6 months) MDD patients and 616 healthy controls (no lifetime depressive and anxiety disorder) at baseline, assessed using the DSM-IV-based Composite International Diagnostic Interview (CIDI, version 2.1) [6]. Recruitment of current MDD patients was mainly from specialized (54.6\%) and primary $(37.0 \%)$ care settings. Remitted MDD patients and controls were mainly recruited from primary care (54.8 and $21.6 \%$ ) and the community (45.0 and 78.4\%).

Common somatic diseases were assessed by a face-to-face interview. Somatic disorders were considered present when participants reported a diagnosis of common specific somatic diseases and for which they reported to receive medical attention (i.e., under treatment by a physician or receiving medication specifically for that reported somatic disease). We used somatic disease categories as categorized previously [7]: cardiometabolic, respiratory, musculoskeletal and digestive diseases, and cancer. An "any somatic disease" variable was created by combining the information from these somatic disease categories, and was dichotomized into "no onset of any somatic disease" ( 0 ) or "onset of $\geq 1$ somatic diseases" (1).

The 30-item self-report Inventory of Depressive Symptomatology (IDS), a reliable and valid instrument [8], was used to assess depression characteristics: overall depression severity (total IDS score, range 0-84), depressive symptom clusters (classification of 30 individual IDS items into a mood, cognitive and somatic/vegetative cluster), and individual depressive symptoms (30 individual IDS items scored on a $0-3$ (from not at all to severe) scale, and considered present when scored $\geq 2$ (i.e., moderate or severe).

The 6-year incidence of any somatic disease and the somatic disease categories were compared between current and remitted MDD persons with controls in only those who were free of that particular somatic disease at baseline. Multivariable Cox regression analyses were used and adjusted for sociodemographics and lifestyle. Also, the 6-year incidence of any somatic disease was further examined in relation to clinical depression characteristics in the total sample that was initially free of any somatic disease at baseline.

Current MDD patients had a significantly higher 6-year incidence of any somatic disease $(\mathrm{HR}=1.37,95 \% \mathrm{CI}=1.06-1.77)$, cardiometabolic diseases $(\mathrm{HR}=1.78,95 \% \mathrm{CI}=1.21-2.60)$, musculoskeletal diseases $(\mathrm{HR}=1.74,95 \% \mathrm{CI}=1.23-2.47)$ and digestive diseases $(\mathrm{HR}=1.78,95 \% \mathrm{CI}=1.20-2.64)$ than controls after adjustment for sociodemographics and lifestyle, but not of respiratory diseases $(\mathrm{HR}=1.63,95 \% \mathrm{CI}=0.95-2.80)$ and cancer $(\mathrm{HR}=$ $1.07,95 \%$ CI $=0.71-1.61$ ) (see online suppl. Table S1). Remitted MDD persons versus controls showed increased somatic disease incidence risks, although they were nonsignificant. Analyses restricted to only medication-confirmed somatic disease incidence (see online suppl. material) or with additional adjustment for antidepressant use (data not shown) did not yield different results.

Within the entire sample that was initially free of any somatic disease $(n=1,327)$, higher overall depression severity predicted a higher 6-year incidence of any somatic disease in a dose-response manner (standardized total IDS score $\mathrm{HR}=1.18$, 95\% CI $=1.04-$ 1.33), and a higher incidence of any somatic disease was associated with the mood symptom cluster $(\mathrm{HR}=1.13,95 \% \mathrm{CI}=1.02-1.25)$ and somatic/vegetative symptom cluster $(\mathrm{HR}=1.18,95 \% \mathrm{CI}=$ 1.07-1.31) in adjusted models (Fig. 1, see online suppl. Table S6).

\section{KARGER}

E-Mail karger@karger.com www.karger.com/pps
C) 2018 The Author(s)

Published by S. Karger AG, Basel

Karger

Open access

This article is licensed under the Creative Commons AttributionNonCommercial-NoDerivatives 4.0 International License (CC BYNC-ND) (http://www.karger.com/Services/OpenAccessLicense) Usage and distribution for commercial purposes as well as any distribution of modified material requires written permission.
Roxanne Gaspersz, MD

Department of Psychiatry, VU University Medical Center Postbus 74077

NL-1070 BB Amsterdam (The Netherlands)

E-Mail f.lamers@ ggzingeest.nl 


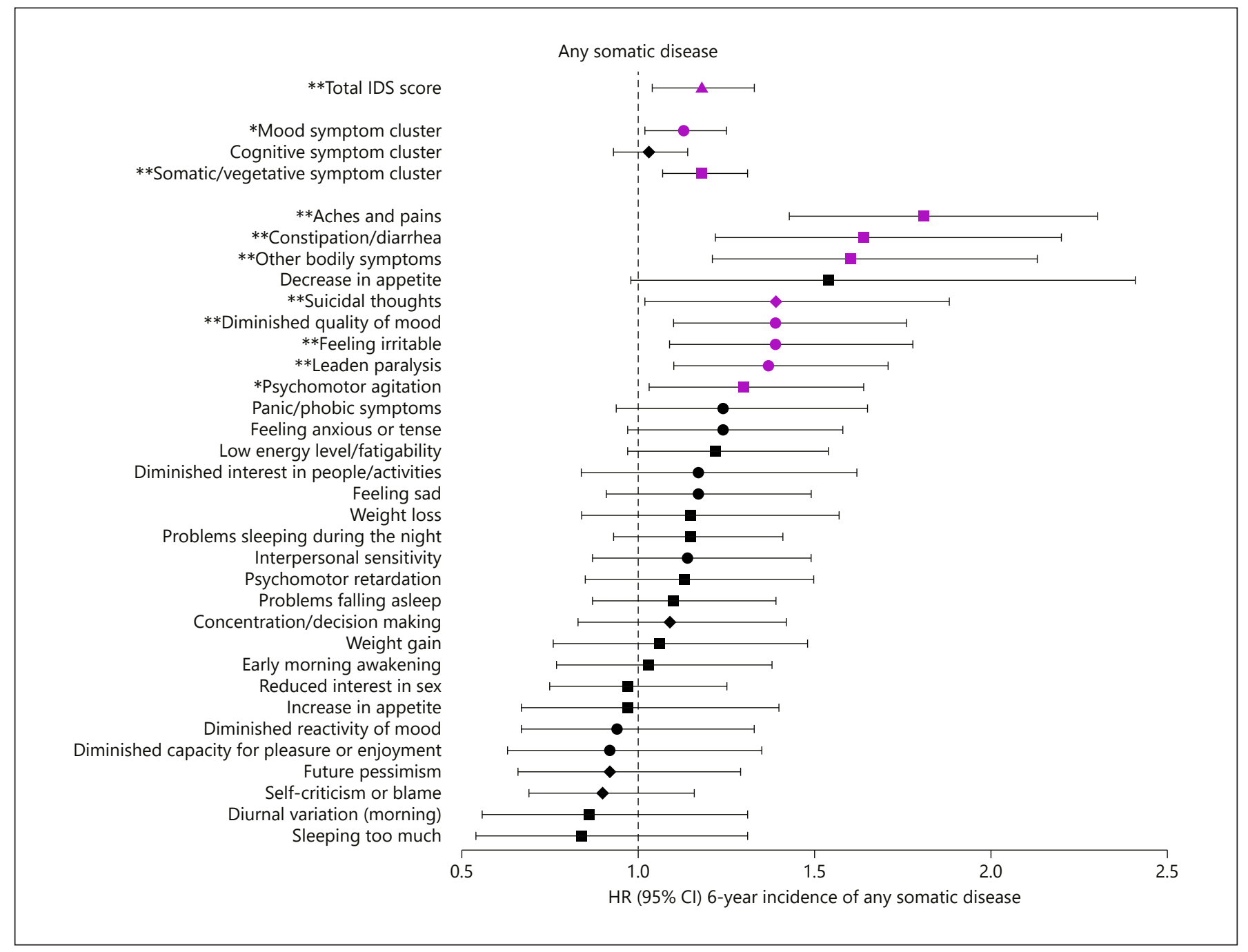

Fig. 1. Adjusted hazard ratios for 6-year incidence of any somatic disease by IDS depression severity, symptom clusters and individual symptoms within the total sample that was initially free of any somatic disease $(n=1,327)$. CI, confidence interval; IDS, Inventory of Depressive Symptomatology; HR, hazard ratio; MDD, major depressive disorder; the triangle represents total IDS score, circles represent depressive mood symptoms, diamonds represent

A higher incidence of any somatic disease was associated with the individual mood symptoms "diminished quality of mood" $(\mathrm{HR}=$ $1.39,95 \% \mathrm{CI}=1.10-1.76)$, "feeling irritable" $(\mathrm{HR}=1.39,95 \% \mathrm{CI}=$ $1.09-1.78)$ and "leaden paralysis" ( $\mathrm{HR}=1.37,95 \% \mathrm{CI}=1.10-1.71)$ and the somatic/vegetative symptoms "aches and pains" (HR = $1.81,95 \% \mathrm{CI}=1.43-2.30)$, "constipation/diarrhea" $(\mathrm{HR}=1.64$, $95 \% \mathrm{CI}=1.22-2.20)$, "other bodily symptoms" ( $\mathrm{HR}=1.60,95 \% \mathrm{CI}$ $=1.21-2.13)$ and "psychomotor agitation" $(\mathrm{HR}=1.30,95 \% \mathrm{CI}=$ 1.03-1.64). When examining MDD subtypes, we could not confirm that MDD patients with or without anxious distress and those with atypical versus melancholic symptoms did differ in the incidence of somatic diseases (see online suppl. Table S7).

Impact of Depression on Somatic Disease Incidence depressive cognitive symptoms, and squares represent depressive somatic/vegetative symptoms. Based on Cox regression analyses. Adjusted for sociodemographics (age, sex, education) and lifestyle (smoking status, alcohol intake, physical activity and body mass index). Total IDS score and IDS symptom clusters were standardized; IDS items were dichotomized. Error bars represent 95\% CIs. Purple estimates are significant $(p<0.05) .{ }^{*} p<0.05,{ }^{* *} p<0.01$.

Our finding of current MDD increasing the 6-year incidence of a multitude of common somatic diseases is in line with previous research $[1,2]$. That remitted MDD persons also had increased somatic disease incidence risks albeit nonsignificant ones, is in line with our finding of a dose-response relationship between overall depression severity and somatic disease incidence, suggesting that possible residual depressive symptoms in remitted MDD persons are contributing to the incidence of somatic diseases. One study also found that current but not remitted depression is a strong predictor for all-cause mortality after adjustment for cardiovascular and lifestyle factors which indicate that the effect of depression decreases after remission, possibly due to an increased vulnerabil- 
ity of persons with a current depressive episode and potential resilience of persons who achieved remission [9]. Current MDD patients may also have a greater sensibility to somatic symptoms and make use of health care more often than those with remitted MDD, possibly resulting in a higher somatic disease incidence in currently depressed patients.

Our finding that somatic/vegetative depressive symptoms seem to contribute to a higher somatic disease incidence is in line with a meta-analysis showing that in patients with heart disease, somatic depressive symptoms were associated with cardiovascular prognosis, unlike cognitive depressive symptoms [10]. Possibly, some of these somatic/vegetative symptoms may be prodromal symptoms of a somatic disease instead of actual depressive symptoms, which may lead to an overestimation of the found association between somatic/vegetative symptoms and somatic disease incidence. Several mood symptoms were associated with a higher onset risk of somatic diseases. An explanation may be lower selfcare due to mood symptoms which will ultimately lead to somatic disease developments. Future research should examine by which mechanisms somatic/vegetative and mood depressive symptoms may contribute to higher somatic disease onset risks, to inform tailored prevention or treatment strategies.

To conclude, having current MDD increases subsequent onset risks of a multitude of somatic diseases, which was not restricted to one single disease category (cardiometabolic, musculoskeletal and digestive diseases, but not of respiratory diseases and cancer). Persons with remitted MDD also showed increased 6-year incidence rates of somatic diseases, albeit nonsignificant ones. Depressive subtypes did not differ in their somatic disease incidence risks as compared to controls. Higher depression severity showed a doseresponse relationship with higher somatic disease incidence. Depressive subtypes (i.e., MDD with anxious distress, atypical or melancholic features) did not substantially differ in their somatic disease incidence risks. However, both mood and somatic/vegetative depressive symptom dimensions seemed to contribute to higher somatic disease onset risks. Our results suggest that current MDD patients, specifically those with high depression severity, and mood and somatic/vegetative symptoms should be monitored more closely and routinely screened on somatic disease comorbidity.

\section{Acknowledgment}

The infrastructure for the NESDA study (www.nesda.nl) is funded through the Geestkracht program of the Netherlands Organization for Health Research and Development (ZonMw, grant No. 10-000-1002) and through participating universities (VU University Medical Centre, Leiden University Medical Centre, University Medical Centre Groningen). Janssen Research \& Development LLC, Titusville, NJ, USA, contributed advisory input to the conducted analyses and provided financial support for the conduct of the data analyses; however, Janssen did not have direct access to the data and was not involved in the conduct of the data collection, management and analyses.

\section{Disclosure Statement}

Dr. Penninx has received (nonrelated) research funding from Jansen Research and Development LLC and Boehringer Ingelheim. Dr. Lamers has received funding from the European Union Seventh Framework Programme (FP7/2007-2013) under grant agreement No. PCIG12-GA-2012-334065. Dr. Beekman has served as a speaker for Lundbeck. All other authors reported no financial interests or potential conflicts of interest.

\section{References}

1 Penninx BWJH, Milaneschi Y, Lamers F, Vogelzangs N: Understanding the somatic consequences of depression: biological mechanisms and the role of depression symptom profile. BMC Med 2013;11:129.

2 Evans DL, Charney DS, Lewis L, Golden RN, Gorman JM, Krishnan KRR, Nemeroff CB, Bremner JD, Carney RM, Coyne JC, Delong MR, Frasure-Smith N, Glassman AH, Gold PW, Grant I, Gwyther L, Ironson G, Johnson RL, Kanner AM, Katon WJ, Kaufmann PG, Keefe FJ, Ketter T, Laughren TP, Leserman J, Lyketsos CG, McDonald WM, McEwen BS, Miller AH, Musselman D, O'Connor C, Petitto JM, Pollock BG, Robinson RG, Roose SP, Rowland J, Sheline Y, Sheps DS, Simon G, Spiegel D, Stunkard A, Sunderland T, Tibbits PJ, Valvo WJ: Mood disorders in the medically ill: scientific review and recommendations. Biol Psychiatry 2005;58:175-189.

3 Patten SB, Williams JVA, Lavorato DH, Modgill G, Jette N, Eliasziw M: Major depression as a risk factor for chronic disease incidence: longitudinal analyses in a general population cohort. Gen Hosp Psychiatry 2008; 30:407-413.

4 Lamers F, Vogelzangs N, Merikangas KR, de Jonge P, Beekman ATF, Penninx BWJH: Evidence for a differential role of HPA-axis function, inflammation and metabolic syndrome in melancholic versus atypical depression. Mol Psychiatry 2013;18:692-699.

5 Penninx BW, Beekman AT, Smit JH, Zitman FG, Nolen WA, Spinhoven P, Cuijpers P, de Jong PJ, van Marwijk HW, Assendelft WJ, van der Meer K, Verhaak P, Wensing M, de Graaf R, Hoogendijk WJ, Ormel J, van Dyck R; NESDA Research Consortium: The Netherlands Study of Depression and Anxiety (NESDA): rationale, objectives and methods. Int J Methods Psychiatr Res 2008;17:121-140.

6 Wittchen HU: Reliability and validity studies of the WHO - Composite International Diagnostic Interview (CIDI): a critical review. J Psychiatr Res 1994;28:57-84.

7 Gerrits MM, van Oppen P, van Marwijk HW, van der Horst H, Penninx BW: The impact of chronic somatic diseases on the course of depressive and anxiety disorders. Psychother Psychosom 2013;82:64-66.

8 Rush AJ, Gullion CM, Basco MR, Jarrett RB, Trivedi MH: The Inventory of Depressive Symptomatology (IDS): psychometric properties. Psychol Med 1996;26:477-486.

9 Lasserre AM, Marti-Soler H, Strippoli MP, Vaucher J, Glaus J, Vandeleur CL, Castelao E, Marques-Vidal P, Waeber G, Vollenweider P, Preisig M: Clinical and course characteristics of depression and all-cause mortality: a prospective population-based study. J Affect Disord 2016;189:17-24.

10 De Miranda Azevedo R, Roest AM, Hoen PW, de Jonge P: Cognitive/ affective and somatic/affective symptoms of depression in patients with heart disease and their association with cardiovascular prognosis: a meta-analysis. Psychol Med 2014;44:2689-2703. 